\title{
Museos, comunicación y educación: una experiencia con futuros maestros de primaria
}

\author{
Museums, communication and education: an experience with future \\ primary school teachers
}

\section{Magdalena Castejón Ibáñez}

Universidad de Murcia, mmagdalena.castejon@um.es

\begin{abstract}
Resumen
El texto que se presenta refleja parte de los resultados obtenidos en una pequeña investigación realizada con el alumnado de la asignatura Juegos Cooperativos de Expresión Artística, perteneciente al Grado de Educación Primaria de la Universidad de Murcia. Dicho estudio ha tenido como objetivo, analizar la relación entre los estudiantes de esta carrera universitaria y futuros maestros con el ámbito de los museos. Para obtener la información requerida, se plantean dos tipos de instrumentos de recogida de datos: por un lado, una encuesta digital de tipo cuantitativo y cualitativo y por otra parte, el análisis de contenido de la opinión de los alumnos tras la realización de una práctica vinculada al desarrollo de una actividad colaborativa en una institución museística.
\end{abstract}

En la encuesta digital se estudian las siguientes dimensiones: "Perfil", "Relación de ocio entre futuro docente y museos", "Los museos como recurso en la formación del profesorado", "Los museos como recurso educativo en la escuela primaria" y "Museos, profesorado y nuevas tecnologías". Este texto se centrará en analizar la última de estas dimensiones, así como en la observación de las valoraciones subjetivas de los alumnos en torno a las actividades vinculadas al arte realizadas en colaboración entre contextos formales (colegios) y no formales (museos y centros culturales).

Los resultados de este estudio reflejan entre otras conclusiones, la dificultad de tejer lineas de colaboración y comunicación entre el ámbito educativo formal y no formal o la necesidad de actualizar la presencia digital de determinados museos para atraer el interés de colectivos jóvenes, como son los futuros docentes. 
Museos, comunicación y educación: una experiencia con futuros maestros de primaria.

Esta investigación se plantea como una primera toma de contacto con la problemática, planteando las bases sobre las que seguir trabajando en pro de una mejora de la comunicación entre museos, universidad y educación formal.

Palabras clave: Museos; tecnología; comunicación; educación primaria; educación no formal

\begin{abstract}
The text showed here reflects part of the results obtained in a short research carried out with a sample of students of the Cooperative Games of Artistic Expression subject belonging to the Primary Education Degree of the University of Murcia. The key objective of this research was to analyze what kind of relationship there are between the students of this university career as future teachers, and the museum scope. We obtained the required information from two different types of data collection instruments: on the one hand, a quantitative and qualitative digital survey, and on the other hand, the content analysis of the opinion of the students, once they had completed a task linked to the development of a collaborative activity done in a museum institution.
\end{abstract}

The following dimensions are studied in the digital survey: "Profile", "Leisure relationship between future teachers and museums", "Museums as a resource in teacher training", "Museums as an educational resource in primary school" and "Museums, teachers and new technologies ". This text will focus on analyzing the last of these dimensions, as well as on observing the subjective evaluations of the students regarding the activities related to art carried out in collaboration between formal (schools) and non-formal (museums and cultural centers) contexts. .

The results of this study reflect, among other conclusions, the difficulty of weaving lines of collaboration and communication between the formal and non-formal educational sphere or the need to update the digital presence of certain museums to attract the interest of young groups, such as future ones. teachers.

This research is proposed as a first contact with the problem, setting the bases on which to continue working in favor of an improvement in communication between museums, universities and formal education.

Keywords: Museums; technology; communication; primary education; Informal education 


\section{Introducción}

Ante la reciente situación sanitaria ocurrida a nivel mundial a causa del virus COVID 19 y las consecuencias socioeconómicas derivadas, determinados contextos se han planteado cómo hacer frente a las dificultades surgidas con el objetivo de adaptarse y no naufragar en el camino.

Los museos no han sido una excepción, y han tenido que reforzar su presencia digital para poder continuar la comunicación con su público. Ciertas instituciones han podido resolver la conjetura de forma positiva, llegando a ofrecer nuevos recursos para conectar con la ciudadanía. Otros en cambio, se han visto obligados a cerrar temporalmente o incluso definitivamente, lo que ha derivado en la necesidad de redefinir el concepto de museo, algo que ya venía siendo requerido años atrás, tanto por los expertos como por la propia sociedad (Aguirre, 2020).

La relación entre museos y público ha sido desde los inicios de la institución, uno de los objetivos más importantes a resolver teniendo que considerar continuamente los avances y cambios progresivos en la sociedad y por tanto, su forma de comunicarse y educarse. La sociomuseología, surgida a finales del siglo XX de mano de Fernando Santos Neves (Stoffel, 2012), plantea precisamente ese cambio necesario al proponer conectar con la ciudadanía haciéndola partícipe de los procesos culturales.

La institución museística ha querido priorizar su enfoque educativo en las últimas décadas, y determinados espacios como el Museo Thyssen o el Museo Reina Sofía, han logrado crear potentes departamentos didácticos que replantean la práctica educativa, suponiendo una línea de trabajo por la que seguir indagando. Tal y como indica Vidagañ $(2019$, p. 37) “entender la educación en los museos centrada en el proceso artístico y no en el objeto permite hacer propuestas educativas en las que el público participa de forma activa", favoreciendo así el poder entender de forma profunda y crítica el propio desarrollo creativo, generador a su vez de identidades socioculturales. El museo se debe pensar desde una perspectiva de mediación crítica, "que proponga estrategias para que no solo el patrimonio sea más accesible, sino para que se reflexione sobre la propia condición del individuo dentro de un entramado social cada vez más diverso y complejo" (González- García, 2019,p.203).

No obstante, en términos generales, la educación en museos sigue planteando actuaciones bajo una estela tradicional que repite los dicursos establecidos, dejando a un lado la perspectiva crítica, a lo que se suma la falta de conexión con los centros para la educación formal. Un ejemplo lo encontramos en la formación sobre museos que se imparte en las universidades, y en concreto, la enfocada a los que serán los educadores del futuro. Tal como confirman Melgar y Elisondo (2017, p.31), "los museos constituyen contextos poderosos para aprender ya sea en complementación con la educación formal o porque las personas se acercan a ellos por libre elección", por lo que resulta de suma importancia, la perspectiva con la que deben conocerse estos espacios por parte de los docentes de las siguientes generaciones. 
Esta situación se desencadena desde el inicio en que un niño en edad escolar es "llevado" por el centro educativo correspondiente a realizar una visita a un museo, por lo general de su entorno, desarrollando actividades que no implican un modelo de aprendizaje activo ni por tanto, atractivo para el discente. Si además, se complementa con la falta de interés o quizá la falta de oferta para desarrollar actuaciones en familia en estos espacios, lo que se obtiene es un futuro jóven y posterior adulto, que no sentirá un mínimo interés por las instituciones culturales, de lo que se deduce que la problemática entre museos y eduación no se ha trabajado hasta entonces lo suficiente (Baz y Sánchez, 2020).

El cambio de concepto y por tanto, de estructura, funciones y metodología del museo, deberá tener muy presente la fuerte irrupción de la tecnología como medio de conectar con las audiencias, no solo a través de las distintas plataformas y aplicaciones de social media, empleadas para difundir sus activididades, sino en la propia museografía de las exposiciones, ya que las nuevas generaciones convivirán con un mundo intrínsecamente tecnológico.

El escaso contacto con este terreno de gran número de museos, está repercutiendo ya en la percepción que los públicos jóvenes tienen de estas instituciones. Si a ello se suma, la escasa presencia del museo como recurso no formal complementario en los planes formativos de los estudiantes de educación, surgen docentes cuya perspectiva de estos espacios dista mucho de las posibilidades reales que la institución cultural ofrece.

Los museos no tienen que convertirse en extensiones de la escuela, sino que deben aprovechar ese caracter no formal que los define para plantear actuaciones significativas para el alumnos, en conexión directa con los centros formales. Para ello, sería muy oportuno que tal y como indican Baz y Sánchez (2020, p. 199), entre otras medidas "existiera una política que articulara una formación de públicos desde el ámbito escolar. Deberíamos de procurar que desde las aulas se comprendieran conceptos básicos relacionados con los museos: curador, cédulas, museografía, museología, entre otros”. En este sentido, resultará imprescindible, que el profesorado conozca y comparta el interés por estas instituciones, lo que se traduce en una necesaria intensificación del conocimiento sobre las posibilidades educativas de los centros museísticos en la formación de los maestros y maestras.

Este breve estudio se plantea como un modo de tomar perspectiva sobre la problemática observada en cuanto a la relación entre educación formal y no formal (museos), y en concreto, sobre los canales de comunicación y colaboración entre ambos sectores. Se toma en cuenta la opinión de un grupo de estudiantes de último curso del Grado en Educación Primaria de la Universidad de Murcia, para valorar su punto de vista en cuanto a considerar las instituciones culturales como un recurso relevante en su labor como docentes en un futuro próximo.

\section{Objetivos}

Este estudio se propone como una aproximación a la problemática detectada en torno a la relación entre instituciones museísticas, formación del profesorado y nuevas tecnologías de 
la comunicación. Su fin principal es constatar las impresiones detectadas por medio de la observación y poder plantear las bases para una investigación más profunda.

Los objetivos generales del estudio han sido:

1. Conocer el perfil de los estudiantes de Educación Primaria de la asigantura de Juegos Cooperativos de Expresión Artística

2. Descubrir la relación entre los museos y los futuros docentes a nivel de ocio

3. Analizar la valoración de la formación del profesorado sobre museos

4. Estudiar la opinión de los estudiantes a cerca de los museos como recurso didáctico en educación primaria

5. Considerar la relación actual entre museos, nuevas tecnologías y profesorado.

6. Conocer la apreciación de los alumnos sobre las actividades vinculadas al arte realizadas en colaboración entre contextos formales (colegios) y no formales (museos y centros culturales).

En cuanto a los objetivos específicos de este texto, en relación con el quinto y el sexto objetivos generales, se plantean los siguientes:

5.1. Descubrir si los futuros docentes conocen los recursos educativos presentes en los medios digitales de las instituciones museísticas

5.2. Conocer la valoración de los estudiantes sobre la disposión de los museos a ofrecer material educativo al profesorado

5.3. Analizar la opinión sobre la difusión y comunicación de las actividades de las instituciones musesíticas

6.1. Considerar la visión de los alumnos en cuanto a las actividades colaborativas entre museos y educación formal

\section{Desarrollo de la innovación}

Con el objetivo de evaluar la relación entre museos, futuro profesorado y nuevas tecnologías, se propone la realización de una breve investigación en la que participarían los alumnos de la asignatura de Juegos Cooperativos de Expresión Artística de la Mención de Recursos Educativos para la Escuela y el Tiempo Libre.

El estudio se lleva a cabo durante el trascurso de una práctica propuesta al alumnado que tenía como objetivo diseñar una actividad /juego de tipo cooperativo enfocado al ámbito de educación primaria, cuyo requisito concreto era ser desarrollada en un espacio museístico.

\subsection{Metodología}

Se plantea una metodología mixta dividida en dos fases. 
En primer lugar se llevaría a cabo un estudio de tipo cuantitativo y cualitativo a través de un cuestionario suministrado por medio de la aplicación digital de la Universidad de Murcia https://encuestas.um.es/. El diseño del instrumento de recogida de datos se dividiría en 5 dimensiones con un total de 14 preguntas, siendo dos de ellas con respuesta abierta y el resto cerrada, con una sola posibilidad de elección. La propia aplicación estadística de la universidad facilitaría los resultados tanto en tabla de datos como en gráfica, por lo que no fue preciso el empleo de otro software distinto para su análisis.

Esta primera parte del estudio se llevaría a cabo al inicio de la propuesta práctica en el aula, en el momento en que los alumnos afrontan el proceso de contextualización y búsqueda de información para su proyecto. El cuestionario es suministrado a los estudiantes de forma digital con acceso a través del correo de la universidad y son contestados en el plazo de una semana.

Por otro lado, tras la realización de la práctica, una vez conocido algo más el contexto estudiado, se propone a los alumnos que respondan de forma individual, a través de los portafolios del proyecto entregado, a la siguiente cuestión:

Tras la realización de esta práctica, escribe tu reflexión personal sobre las actividades vinculadas al arte realizadas en colaboración entre contextos formales (colegios) y no formales (museos y centros culturales).

Las respuestas obtenidas se analizarán de forma cualitativa, extrayendo las categorías más destacadas y reitredas por los participantes.

\subsection{Participantes}

El cuestionario fue suministrados a los 51 alumnos matriculados en la asignatura, de los cuales respondieron tanto al cuestionario como a la observación posterior, un total de 48 estudiantes. El perfil de los participantes fue el siguiente:

Un $67 \%$ de los estudiantes partícipes del estudio eran mujeres, y por tanto mayoría. En cuanto a la edad, una alto porcentaje (94\%), se sitúa en la franja entre los 18 y los 25 años, quedando dos estudiantes entre 26 y 40 años y uno de más de 40 . En relación a la actividad que llevan a cabo en el momento del estudio, un $69 \%$ confirma ser estudiante, quedando un $31 \%$ que combina su formación con una actividad laboral.

\section{Resultados}

A continuación se muestran los resultados de las dos partes de este estudio: por un lado, los datos obtenidos de los cuestionarios suministrados en formato digital a los alumnos partícipes, en concreto, los correspondientes a la dimensión que comprende la relación entre museos, profesorado y nuevas tecnologías. Por otra parte, la información recogida y analizada de las opiniones y valoraciones en torno a la problemática estudiada por parte de los estudiantes, tras la realización del proyecto vinculado a museos en el aula. 


\subsection{Cuestionario digital}

El diseño del cuestionario se compone de cinco dimensiones a estudio diferentes, esto es:

1. Perfil

2. Relación de ocio entre futuro docente y museos

3. Los museos como recurso en la formación del profesorado

4. Los museos como recurso educativo en la escuela primaria

5. Museos, profesorado y nuevas tecnologías

Dentro de la última dimensión denominada "Museos, profesorado y nuevas tecnologías", se analizan tres cuestiones diferentes:

1. “¿Conoces los recursos educativos que ofrecen las webs y redes sociales de algunos museos para el profesorado?"

2. "Como futuro docente, ¿crees que los museos deberían ofrecer más recursos educativos digitales a los docentes?"

3. “¿Crees que los museos de tu entorno deberían mejorar la difusión digital (Web, redes sociales) de sus actividades?"

\subsubsection{El museo como recurso didáctico}

Los resultados de la primera pregunta (Tabla 1, Figura 1), confirman que hasta un 50\% de los estudiantes desconoce en el momento de la investigación los recursos educativos que ofrecen los medios digitales de las instituciones museísticas. Además, un 41,7\% restante, indica que los ha conocido a raíz de la propuesta práctica que desarrollan en ese momento en la asignatura Juegos Cooperativos de Expresión Artística. Tal y como se puede observar, tan solo 4 alumnos menciona tener constancia de estas opciones didácticas de forma previa.

Tabla.1. Resultados de la cuestión, “¿Conoces los recursos educativos que ofrecen las webs y redes sociales de algunos museos para el profesorado?"

\begin{tabular}{llcc}
\hline Cod. & Respuesta & Total & \% \\
\hline A & No, los desconozco & 24 & 50 \\
B & $\begin{array}{l}\text { Sí, los he descubierto a partir de la práctica realizada en la } \\
\text { asignatura Juegos Cooperativos }\end{array}$ & 20 & 41,7 \\
C & Sí, ya los conocía & 4 & 8,3 \\
\hline
\end{tabular}


Museos, comunicación y educación: una experiencia con futuros maestros de primaria.

\subsubsection{Recursos digitales y profesorado}

La siguiente cuestión analiza la opinión de los estudiantes de educación primaria sobre la facilitación de recursos didácticos por parte de los museos al profesorado, de tipo digital. La respuesta mayoritaria es positiva, considerando mas del 79\% de los encuestados que sería muy útil para su labor como docente. En cambio algo más de un $20 \%$ restante, opina que desconoce los recursos que las instituciones museísticas pueden ofrecer al profesorado de primaria.

Tabla.2. Respuesta a la cuestión, Como futuro docente, ¿crees que los museos deberían ofrecer más recursos educativos digitales a los docentes?

\begin{tabular}{llll}
\hline Cod. & Respuesta & Total & $\%$ \\
\hline A & No, creo que es correcto & 0 & 0 \\
B & No lo sé, no lo conozco bien & 10 & 20,8 \\
C & Sí, sería muy útil & 38 & 79,2 \\
\hline
\end{tabular}

\subsubsection{Difusión y comunicación digital en museos}

La última cuestión llevada a estudio analiza la capacidad de difusión y comunicación digital de los museos del entorno de los estudiantes (diversas poblaciones de la Región de Murcia). Hasta un 77\% valora que la mejora en la difusión de la actividad museística sería muy útil para ampliar opciones en su labor como futuros profesores. Además, casi un 17\% opina que les gustaría que esa comunicación digital fuera más efectiva para poder conocer las opciones de ocio cultural de esas instituciones.

Tabla 3. Resultados de ¿Crees que los museos de tu entorno deberían mejorar la difusión digital (Web, redes sociales) de sus actividades?

\begin{tabular}{llll}
\hline Cod. & Respuesta & Total & $\mathbf{\%}$ \\
\hline A & No, creo que es suficiente & 0 & 0 \\
B & No lo sé, no lo conozco bien & 3 & 6,2 \\
& Sí, sería muy útil para conocer recursos para nuestro trabajo & 37 & 77,1 \\
C & como docentes & & \multirow{2}{*}{8} \\
D & Sí, estaría muy bien para conocer las actividades de ocio & 8 & 16.7 \\
\hline
\end{tabular}




\subsection{Análisis de contenido de opiniones}

Como se ha mencionado anteriormente y dado el enfoque de este artículo y su extensión, se comentan a continuación los resultados del análisis del contenido de las opiniones de los estudiantes, de modo resumido a modo de avance.

Destaca la opinión generalizada de los estudiantes por incluir a los museos como recurso en su práctica docente futura, habiendo descubierto su potencial a través de la práctica realizada y la investigación previa asociada. Los alumnos lo comentan así:

"Realizada y trabajada esta práctica, no me cabe duda alguna en un futuro llevar a cabo una actividad así con mis alumnos"

Otro aspecto que mencionan numerosos estudiantes es la necesidad de contextualizar la visita en el aula para obtener un aprendizaje más significativo:

"Para utilizar este recurso (actividades en museos) y que los alumnos presenten interés por el lugar visitado y su contenido sea significativo, debes realizar una buena planificación de la salida donde conectes el contenido explicado con la temática del museo, tenga obras llamativas y desarrolles actividades relacionadas con la visita"

Los alumnos basan esta opinión principalmente en su experiencia como estudiantes en la etapa primaria/secundaria de la que no guardan sensaciones y recuerdos especialmente significativos:

"Dando un salto en el tiempo, mi experiencia personal en la escuela relacionada con este recurso ha sido siempre bastante pobre. Recuerdo las salidas en las que visitamos algún museo sin tener esto ninguna relación con lo que estábamos estudiando en el aula."

Con el fin de modificar esta tendencia, los alumnos apuestan por una mayor presencia de este tipo de actuaciones en el currículum de primaria:

"En cambio, en el actual sistema educativo debería fomentarse las visitas a los museos ya que, tras la realización de esta práctica, he podido darme cuenta de todo lo que un museo puede aportar a nivel personal y educativo a través de sus exposiciones"

Del mismo modo, también insisten en la necesidad de que desde la formación del profesorado se fomenten las estrategias educativas que empleen al museo como recurso didáctico, pudiendo conocer así todas las opciones de aprendizaje que ofrece:

"El potencial didáctico de los museos es un aspecto poco valorado en la enseñanza, por muy obvio que pueda parecer en los modelos de enseñanza actuales. Prueba de ello es la poca repercusión que los museos han tenido en la formación de la mayoría de los docentes en formación" 
Diversos alumnos correoboran la falta de conocimiento sobre las posibilidades educativas que ofrecen los museos, y su descubrimiento a través de la indagación previa a la práctica:

"antes de comenzar con el diseño de la actividad, estuvimos buscando y mirando museos y pude observar la gran cantidad de museos que ofrecen actividades para los alumnos de Primaria y Secundaria. Por ello, ahora que conozco este método, sé que lo utilizaré en mi futura clase de Primaria.":

"Antes de esta práctica desconocía cómo se podían trabajar profundamente los museos de forma interesante y motivadora para los niños, y que fuera más allá de un simple "día de excursión". En cambio, ahora que tengo conocimiento sobre ello no dudaré en ponerlo en práctica en un futuro cómo maestra, de lo contrario sería un gran error por mi parte"

En definitiva, los estudiantes confirman la oportunidad que plantean las instituciones museísticas al profesorado como medio para incentivar nuevas metodologías docentes en las que el alumno se sienta partícipe de su aprendizaje, creando experiencias significativas en las que se fomente la creatividad, el autoconocimiento o la percepción del entorno cultural, entre otros aspectos:

"Pero había perdido de vista la cantidad de contenidos actitudinales que se trabajan con la visita a un museo de arte: pasando por las normas de conducta y el respeto a las elaboraciones de otra persona, hasta trabajar las emociones según lo que nos inspiran las formas y colores utilizados por el artista"

Las opiniones subjetivas recogidas de los alumnos partícipes de este estudio, confirman los datos obtenidos en las encuestas digitales, lo que a su vez corroboraría la hipótesis inicial sobre la que se ha basado esta breve investigación y que, sin duda, podrá servir de base para un estudio más amplio en el que se analicen los aspectos más destacados resultantes de esta muestra.

\section{Conclusiones}

Los resultados que se han presentado en este texto, plantean la necesidad de continuar trabajando en las líneas de investigación marcadas por este breve estudio.

Por un lado, la constatada falta de información sobre las posibilidades que ofrece el museo como recurso didáctico, queda reflejada con las respuesta de los alumnos, lo que plantea la necesidad de ampliar el conocimiento sobre la función educativa de los espacios museísticos, ya que se siguen percibiendo estos espacios como lugares ajenos a sus intereses.

Por otra parte, la mayoría de estudiantes al ser conscientes de la capacidad educadora de estas instituciones, concibe como necesarios los recursos educativos que se puedan proporcionar a los docentes como complemento a su práctica profesional. En este caso, la labor difusora y didáctica de los museos deberá potenciarse, teniendo en cuanta a este sector de profesionales de la educación, tan relevante para el futuro de la sociedad. 
En cuanto a la comunicación digital de los centros museísticos, es imprescindible que los museos que no priorizan este tipo de medios, replanteen su estrategia sin descuidar por supuesto, otras en la que se lleva a cabo un contacto directo con el público. Considerando que las próximas generaciones entre las que se encuentran los futuros maestros y maestros y los escolares a los que educarán, conocerán el mundo a través de los medios digitales, las instituciones museísticas no podrán dar la espalda a la situación.

La problemática existente en muchas ocasiones, es la dificultad para adaptarse a los cambios sociales al ritmo vertiginoso que acontecen, de igual manera que también ocurre en la instituciones educativas formales. En efecto, ante la grave e insólita situación que se está viviendo a nivel mundial por las limitaciones de actuación que determina el virus COVID 19, las instituciones que ya habían desarrollado avances en cuanto a comunicación y educación a nivel digital, se han adaptado de mejor forma las graves consecuencias que supone el hecho de cerrar los museos.

No obstante que se apuesta por lo digital, no supone olvidar que la prioridad de los museos es convertirse en espacios más permeables y accesibles a los ciudadanos, entendiéndose esto desde todas las perspectivas posibles. Una línea de trabajo será sin duda, la accesibilidad digital, pero otra si cabe más importante, será la conexión a partir de estrategias educativas que favorezcan el pensamiento y por tanto, el aprendizaje crítico y constructivo para con la sociedad futura. En este sentido, la formación del futuro profesorado será determinante para crear nuevas audiencias en ese museo del futuro aún sin definir.

\section{Referencias}

AGUIRRE, M. D. G. (2020) Los museos desde la pandemia. Revista digital Universidad de Guanajuato.

$<$ http://www.cultura.ugto.mx/sites/default/files/descargas/museosygalerias/2020/nov/art iculos_museosylapandemia_2020.pdf)(Consultado el 15 de febrero de 2021)

BAZ SÁNCHEZ, S. G., \& SÁNCHEZ MICHEL, V. (2020). Museos y educación: encuentros y desencuentros (reflexiones para su investigación). Revista de Arte Ibero Nierika, (18), p.

$186-$

204. $<$ http://192.203.177.185/bitstream/handle/ibero/3602/BSSG_Art_01.pdf?sequence= $1 \&$ isAllowed $=\mathrm{y}>$ (Consultado el 15 de febrero de 2021).

GONZÁLEZ-GARCÍA, R.. (2019) "El giro educativo del arte como herramienta para la transformación social en los nuevos museos del siglo XXI". En Pazos-López, A. y Alonso, A. Tak. Museo. Imagen. Sentidos, Monográfico temático, Eikón Imago 14 (2019): 199-216<http://hdl.handle.net/10902/18521> (Consultado el 19 de febrero de 2021)

MELGAR, M. F., \& ELISONDO, R. C. (2017). Museos, formación profesional e innovación educativa en la Universidad. Contextos de Educación, 
Museos, comunicación y educación: una experiencia con futuros maestros de primaria.

$<$ http://www2.hum.unrc.edu.ar/ojs/index.php/contextos/article/view/477> (Consultado el 19 de febrero de 2021).

STOFFEL, M. (2012).De que hablamos cuando hablamos de Sociomuseología. RdM.Revista de Museología, (53), pp. 8-14.

VIDAGAÑ MURGUI, M. I. (2019). Colaboración entre centros escolares y museos. La educación artística desde la Fundación Calouste Gulbenkian Quaderns Digitals, (88) Abril 2019 pp. 35-48 $<$ https://zaguan.unizar.es/record/84341/files/texto_completo.pdf $>$ (Consultado el 19 de febrero de 2021). 